\title{
BONE MINERAL DENSITY IN MASTER CYCLISTS: A 2-YEAR FOLLOW-UP STUDY
}

\author{
T. Abe ${ }^{1,2}$, J.P. Loenneke', V.K. Nahar', M.A. Ford ${ }^{1}$, M.A. Bass ${ }^{1}$, S.G. Owens ${ }^{1}$, M. Loftin ${ }^{1}$
}

\begin{abstract}
Before and after a follow-up period of two-years, six male master cyclists (mean age was 59 years at the start of the study, cycle training; 5-6 hrs/wk) had dual-energy X-ray absorptiometry measured body composition (i.e., areal bone mineral density [aBMD] and appendicular lean soft tissue mass [aLM]) taken. aBMD at the femoral neck and lumber spine were similar between the two measurements, but aLM ( $p=0.056)$ tended to be higher at the 2-year follow-up. There were no significant ( $p>0.05$ ) associations between changes in aLM and aBMD at femoral neck or lumber spine. Male master cyclists who exercise with a mild training volume (5-6 hrs/wk) maintained aBMD at the lumber spine and femoral neck. Furthermore, aLM tended to increase over the 2-year period. Further research is necessary to determine the training volume threshold needed to maintain aBMD in master cyclists.
\end{abstract}

Key words: Master athletes, DXA, training volume, muscle thickness.

\section{Introduction}

To prevent and treat low bone mineral density (BMD), participation in weight bearing exercise has been widely recommended (1). Cross-sectional studies indicate that athletes, in general, have higher values of areal BMD $(\mathrm{aBMD})$ and reduced fracture risk compared to nonathletes $(2,3)$. However, previous studies reported that some endurance athletes, such as long distance runners, and athletes in non-weight-bearing sports have lower values of regional aBMD compared with other athletes and / or non-athlete control (4).

Cycling is a non-weight bearing physical activity that provides minimal load or strain to bone. Although the magnitude of shear loading on the bone from muscle contractions would be related to the amount of activated muscle mass during cycling, many crosssectional studies indicate that young and master cyclists have reduced femoral neck and/or lumber spine aBMD when compared to their non-athlete age-matched counterparts $(5,6)$. Similar results have been observed in longitudinal studies (7-9). For instance, Barry and Kohrt (8) investigated the effects of vigorous cycle

1. Department of Health, Exercise Science, and Recreation Management, School of Applied Sciences, The University of Mississippi, Oxford, MS, USA; 2. Department of Sports and Life Sciences, National Institute of Fitness and Sports in Kanoya, Kanoya, Kagoshima, Japan

Corresponding Author: Takashi Abe, PhD, Department of Sports and Life Sciences, National Institute of Fitness and Sports in Kanoya, Kanoya-shi, Kagoshima 8912393, Japan, E-mail: t12abe@gmail.com training (13.5 hr/wk) on regional aBMD and found that male road cyclists (aged 27 to 44 ) decreased femoral neck aBMD, but did not reach statistical significance in lumber spine aBMD over the course of a competitive season of road cycling (12 months). Similarly, a 12-month follow-up study (9) reported that aBMD at total hip and subtrochanter decreased in female master cyclists (cycle training; $9.6 \mathrm{hrs} / \mathrm{wk}$ ) but maintained in femoral neck aBMD. The training regimen of cyclists varied in the previous cross-sectional and longitudinal studies and it is expected that training volume may affect changes in regional aBMD. For example, in elite athletes exercising with high training volumes, there may be a negative effect on bone (10). Therefore, we hypothesize that master cyclists who are exercising with a moderate training volume (e.g., less than $7 \mathrm{hrs} / \mathrm{wk}$ ) may have positive associations between exercise and aBMD. The purpose of this study was to investigate the changes in femoral neck and lumber spine aBMD and total and regional muscle mass in male master cyclists over a 2-year period.

\section{Methods}

\section{Subjects}

Six male master cyclists volunteered for the study. All master cyclists were members of a local area cycling team and were all training regularly and actively (3-6 times/wk, approximately 5-6 hrs/wk) for, on average, 
Table 1

Changes in body composition and walking performance, and major training programs

\begin{tabular}{|c|c|c|c|}
\hline & \multicolumn{3}{|c|}{ Master Cyclists $(n=6)$} \\
\hline & 2012 & 2014 & P-value \\
\hline Age (yr) & $59(5)$ & $61(5)$ & \\
\hline Standing height (m) & $1.75(0.07)$ & $1.75(0.06)$ & 0.611 \\
\hline Body mass (kg) & $80.8(11.3)$ & $78.3(10.2)$ & 0.273 \\
\hline Body mass index (kg/m2) & $26.3(2.5)$ & $25.4(1.8)$ & 0.257 \\
\hline Body fat $(\%)$ & $21.3(6.8)$ & $19.0(3.7)$ & 0.357 \\
\hline Total lean soft tissue mass (kg) & $59.0(7.4)$ & $59.0(7.6)$ & 0.905 \\
\hline \multicolumn{4}{|l|}{ Muscle thickness (cm) } \\
\hline Anterior thigh (A50) & $5.68(0.48)$ & $5.50(0.32)$ & 0.120 \\
\hline Posterior thigh (P50) & $6.52(0.38)$ & $6.70(0.39)$ & 0.218 \\
\hline \multicolumn{4}{|l|}{ Thigh muscle thickness ratio } \\
\hline A50:P50 & $0.87(0.08)$ & $0.82(0.05)$ & 0.068 \\
\hline \multicolumn{4}{|l|}{ 10-m walking time (s) } \\
\hline Straight & $3.6(0.3)$ & $3.9(0.5)$ & 0.011 \\
\hline Zigzag & $4.8(0.5)$ & $5.0(0.6)$ & 0.025 \\
\hline \multicolumn{4}{|l|}{ Training history } \\
\hline Years of cycling (yr) & $22(12)$ & & \\
\hline Average cycling time (hours/session) & $1.22(0.51)$ & $1.28(0.55)$ & 0.485 \\
\hline Average cycling session (times/wk) & $4.6(1.4)$ & $4.1(1.6)$ & 0.203 \\
\hline Resistance exercise & a & $\mathrm{b}$ & \\
\hline Other type of aerobic exercise & & $\mathrm{b}$ & \\
\hline
\end{tabular}

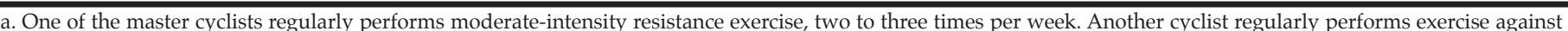

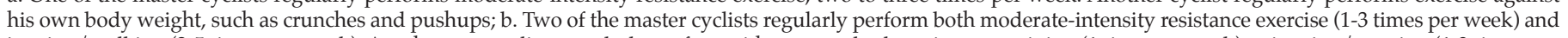

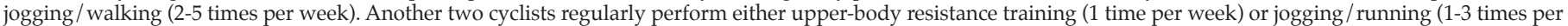
week). One cyclist skipped resistance exercise regimen when he performed it before the initial test.

22 years (range 7-38 years at the start of this study). With the exception of one cyclist, all cyclists had no known neurological, metabolic, or cardiovascular disease and none were taking medications known to affect bone metabolism. One master cyclist had previously suffered from a minor myocardial infarction, but had been training (approximately $6 \mathrm{hrs} / \mathrm{wk}$ ) successfully for 9 years with no complications. Testing was completed in November-December 2012 (initial test) and NovemberDecember 2014 (second test). The study was reviewed and approved by the University's Institutional Review Board and written informed consent was obtained from all participants.

\section{Bone mineral density and body composition measurements}

Subjects underwent dual energy x-ray absorptiometry (DXA) scans (Discovery A, Hologic Inc., Bedford, MA, USA) to determine percent body fat (\% fat), total (tLM, $\mathrm{kg}$ ) and appendicular lean soft tissue mass (aLM, kg), and $\mathrm{aBMD}(\mathrm{g} / \mathrm{cm} 2)$ of the AP lumbar spine (L1-L4) and femoral neck of non-dominant (left) leg's proximal femur. Quality assurance testing and calibration was performed before the data collection to ensure that the DXA was operating properly. Test-retest reliability using intraclass correlation coefficient (ICC3,1), standard error of measurement (SEM), and minimal difference to be considered real were previously reported in the literature (11).

\section{Statistical analysis}

All data are presented as mean and standard deviation. A paired t-test was used to evaluate the difference between a 2-year follow-up testing (initial and second tests). Changes in aLM and aBMD (second test minus initial test) were calculated. Pearson productmoment correlations were performed to determine the relationship between changes in aLM and aBMD at femoral neck or lumber spine. Statistical significance was set at $\mathrm{p}<0.05$. 
Table 2

Changes in appendicular lean soft tissue mass and lumber spine and femoral neck areal bone mineral density

\begin{tabular}{|c|c|c|c|c|c|c|c|c|c|}
\hline \multirow[t]{2}{*}{ Subj. } & \multicolumn{3}{|c|}{ Appendicular LTM (kg) } & \multicolumn{3}{|c|}{ Femoral neck aBMD (g/cm2) } & \multicolumn{3}{|c|}{ Lumber spine aBMD (g/cm2) } \\
\hline & 2012 & 2014 & Diff & 2012 & 2014 & Diff & 2012 & 2014 & Diff \\
\hline A & 23.7 & 25.3 & 1.62 & 0.738 & 0.775 & 0.037 & 0.995 & 1.013 & 0.018 \\
\hline B & 27.0 & 28.3 & 1.29 & 1.039 & 0.998 & -0.041 & 1.332 & 1.319 & -0.013 \\
\hline C & 26.6 & 27.7 & 1.11 & 0.705 & 0.758 & 0.053 & 0.951 & 0.855 & -0.096 \\
\hline D & 32.5 & 33.3 & 0.81 & 0.963 & 0.960 & -0.003 & 1.313 & 1.321 & 0.008 \\
\hline $\mathrm{E}$ & 23.9 & 23.9 & 0.07 & 0.648 & 0.726 & 0.078 & 0.806 & 0.846 & 0.040 \\
\hline $\mathrm{F}$ & 25.2 & 24.8 & -0.34 & 0.713 & 0.717 & 0.004 & 0.922 & 0.905 & -0.017 \\
\hline Mean & 26.5 & 27.2 & 0.76 & 0.801 & 0.822 & 0.021 & 1.053 & 1.043 & -0.010 \\
\hline SD & 3.3 & 3.4 & 0.75 & 0.160 & 0.124 & 0.043 & 0.218 & 0.223 & 0.047 \\
\hline
\end{tabular}

LTM, lean soft tissue mass; aBMD, areal bone mineral density

\section{Results}

The mean age of the six master cyclists was 59 ( $\mathrm{SD} \pm 5$ ) years at the start of the study. Average cycle training distance per session and average number of weekly sessions were maintained during the follow-up period. After the initial test, two cyclists newly began combination training (cycling plus both resistance exercise and jogging). Another cyclist also included running sessions in his training regimen (Table 1).

There were no differences in body mass, BMI, \%fat, and tLM between initial and second tests (Table 1). aBMD at femoral neck $(\mathrm{p}=0.278)$ and lumber spine $(\mathrm{p}=0.625)$ was also similar between the two tests, but aLM $(\mathrm{p}=0.056)$ tended to be higher in the second test than in the initial test (Table 2). There were no significant relationships between changes in aLM and aBMD at femoral neck $(\mathrm{r}=0.184, \mathrm{p}=0.727)$ or lumber spine $(\mathrm{r}=0.189, \mathrm{p}=0.719)$.

\section{Discussion}

In the present study, aLM in four of the six master cyclists increased from 0.8 to $1.6 \mathrm{~kg}(2.5-6.8 \%)$ over the 2-year follow-up period. Only one cyclist had a decline in aLM, which may have been due to reduced cycle training volume and/or a decreased participation in resistance exercise. Thus, our results have reaffirmed that chronic cycle training itself and combination of cycling and moderate-intensity resistance training may play a role to improve or preserve muscle mass in master cyclists (12). However, we did not observe a positive association between increased aLM and aBMD. A study reported that competitive male master cyclists who participated in resistance training or high impact activities had a smaller decline in hip aBMD and a larger increase in spine aBMD over 7 years than those who did not (13). Although resistance training is an effective tool to improve both aBMD and muscle mass, increases in muscle mass do not necessarily produce beneficial changes in aBMD with each individual case.

A study showed that the average annual rate of change at the femoral neck aBMD is $-0.82 \%$ in older men aged 60 years and over (14). In the present study, our results demonstrated that $\mathrm{aBMD}$ at the lumber spine $(-0.5 \%$ per year $)$ and femoral neck $(+1.3 \%$ per year $)$ was maintained over a 2-year follow-up period. In a prospective study by Beshgetoor et al. (7), 12 female master cyclists and 9 non-athletes were followed over an 18 -month period. Femoral neck aBMD was maintained in female cyclists (cycle training; $9.4 \mathrm{hrs} / \mathrm{wk}$ ) but decreased in non-athlete controls. On the other hand, lumber spine aBMD decreased in both female cyclists and controls over the study period. Barry and Kohrt (8) investigated the effects of vigorous cycle training (13.5 hrs/wk) and supplemental calcium on aBMD in male cyclists and found that male cyclists showed significant decreases in femoral neck aBMD but not in lumber spine aBMD despite taking calcium supplementation over the 12-months of follow-up. Sherk et al. (9) recently reported that total hip and subtrochanter aBMD were decreased in female cyclists over 12 months of training and competition (cycle training; $9.6 \mathrm{hr} / \mathrm{wk}$ ), although lumber spine and femoral neck aBMD were maintained. Compared to our master cyclists (cycling training, 5-6 hrs/wk), study participants in other previous studies engaged in a higher training volume of cycling and in many cases those cyclists also performed running and resistance exercise $(8,9)$. A study of male runners reported an inverse association between aBMD and training volume when running mileage exceeded 20 miles/wk (15). High volumes of vigorous exercise could trigger a negative influence in bone metabolism, i.e., increase in bone resorption, and then result in lower aBMD. In addition, exercise-related aBMD in athletes is related to calcium imbalance during training. Several studies $(8,10)$ investigated dermal calcium loss through sweat during 
exercise and a significant relationship between average dermal calcium loss over 2-hour sweat collection and hip aBMD has been observed (8). From the present study, however, it remains unknown what threshold of cycling volume is required to maintain and/or prevent negative effects in aBMD in master cyclists.

In conclusion, this follow-up study of male master cyclists who exercise with a mild training volume maintained $\mathrm{aBMD}$ at the lumber spine and femoral neck. Furthermore, aLM tended to be increased over the 2-year period. Further research is necessary to determine the training volume threshold needed to maintain aBMD in master cyclists.

Acknowledgment: The authors thank the individuals who participated in this study. None of the authors had financial or personal conflict of interest with regard to this study. This study received no specific grant from any funding agency in the public, commercial, or not-for-profit sectors.

\section{References}

1. Kohrt WM, Bloomfield SA, Little KD, Nelson ME, Yingling VR; American College of Sports Medicine. American College of Sports Medicine Position Stand: physical activity and bone health. Med Sci Sports Exerc 2004; 36: 1985-1996.

2. Heinonen A, Oja P, Kannus P, Sievanen H, Manttari A, Vuori I. Bone mineral density of female athletes in different sports. Bone Miner 1993; 23: 1-14.

3. Rutherford OM. Is there a role for exercise in the prevention of osteoporotic fractures? Br J Sports Med 1999; 33: 378-386.
4. Scofield KL, Hecht S. Bone health in endurance athletes: runners, cyclists, and swimmers. Curr Sports Med Rep 2012; 11: 328-334.

5. Campion F, Nevill AM, Karlsson MK, Lounana J, Shabani M, Fardellone P, Medelli J. Bone status in professional cyclists. Int J Sports Med 2010; 31: 511-515.

6. Nichols JF, Palmer JE, Levy SS. Low bone mineral density in highly trained male master cyclists. Osteoporos Int 2003; 14: 644-649.

7. Beshgetoor D, Nichols JF, Rego I. Effect of training mode and calcium intake on bone mineral density in female master cyclists, runners, and non-athletes. Int J Sport Nutr Exerc Metab 2000; 10: 290-301.

8. Barry DW, Kohrt WM. BMD decreases over the course of a year in competitive male cyclists. J Bone Miner Res 2008; 23: 484-491.

9. Sherk VD, Barry DW, Villalon KL, Hansen KC, Wolfe P, Kohrt WM. Bone loss over 1 year of training and competition in female cyclists. Clin J Sports Med 2014; 24: 331-336.

10. Klesges RC, Ward KD, Shelton ML, Applegate WB, Cantler ED, Palmieri GM, Harmon K, Davis J. Changes in bone mineral content in male athletes. Mechanisms of action and intervention effects. JAMA 1996; 276: 226-230.

11. Abe T, Nahar VK, Young KC, Patterson KM, Stover CD, Lajza DG, Tribby AC, Geddam DA, Ford MA, Bass MA, Loftin M. Skeletal muscle mass, bone mineral density, and walking performance in masters cyclists. Rejuvenation Res 2014; 17: 291-296.

12. Ozaki H, Loenneke JP, Thiebaud RS, Abe T. Cycle training induces muscle hypertrophy and strength gain: strategies and mechanisms. Acta Physiol Hung 2015; 102: 1-22.

13. Nichols JF, Rauh KJ. Longitudinal changes in bone mineral density in male master cyclists and nonathletes. J Strength Cond Res 2011; 25: 727-734.

14. Jones G, Nguyen T, Sambrook P, Kelly PJ, Eisman JA. Progressive loss of bone in femoral neck in elderly people: longitudinal findings from the Dubbo osteoporosis epidemiology study. BMJ 1994; 309: 691-695.

15. MacDougall JD, Webber CE, Martin J, Ormerod S, Chesley A, Younglai EV, Gordon CL, Blimkie CJ. Relationship among running mileage, bone density, and serum testosterone in male runners. J Appl Physiol 1992; 73: 1165-1170. 